\title{
Green Synthesis of Silver Nanoparticles by Leaf Extracts of Boerhavia erecta and Spectral Characterization and Their Antimicrobial, Antioxidant ad Cytotoxic Studies on Ovarian Cancer Cell Limes
}

\author{
Sandhya Rani. Palle 1(D), Josthna Penchalaneni 1,* (D), Kousalya Lavudi 1 (D), \\ Susmila Aparna Gaddam ${ }^{2}$ (D), Venkata S Kotakadi 3,*(D), Varadarajulu Naidu Challagundala 4 (D)

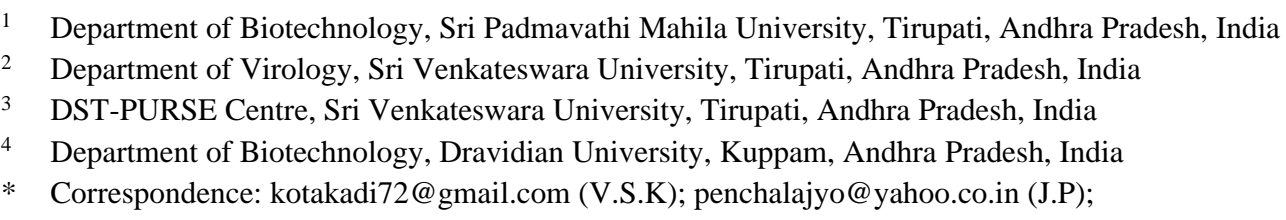

Received: 22.05.2020; Revised: 10.06.2020; Accepted: 11.06.2020; Published: 15.06.2020

\begin{abstract}
The selection of silver metal for the biosynthesis of nanoparticles is a great choice as it exhibits a wide range of applications. Boerhavia Erecta is an extraordinary plant species thatis useful and unique because of its physical characteristics and genetic composition. The current study reported the synthesis of silver nanoparticles by using B. Erecta leaf extract and spectral characterized and studied their properties to target ovarian cancer by antitumorigenic activity. Green synthesized Boerhavia Erecta silver nanoparticles (Be-AgNPs) exhibit the Surface Plasmon resonance phenomenon at $446 \mathrm{~nm}$. The particle size of Be-AgNPs was found to be $15.9 \pm 1 \mathrm{~nm}$ by particle size analyzer technique. The zeta potential of the biosynthesized Be-AgNPs found to be $-36.9 \mathrm{mV}$, which is a high negative charge indicating its stability and polydispersed nature. The FT-IR results confirmed the presence of secondary metabolites and proteins around the green synthesized Be-AgNPs, which are responsible for the reduction and stability of the nanoparticles. The antioxidant study confirmed the high reflection of reduction property of oxygen free radicals, and the antibacterial activity showed moderate activity against both gram-positive and gram-negative microorganisms when compared with standard antibiotics by disc diffusion assay. Anticancer studies reveal that the biosynthesized BeAgNPs were very effective and cytotoxic to ovarian cancer PA-1 cell line at the concentration of 25 $\mu \mathrm{g} / \mathrm{ml}$ confirmed by performing MTT assay. It is concluded that the eco-friendly biosynthesized BeAgNPs show evidence of a high range of anticancer properties against ovarian cancer PA-1 cell lines, antioxidant and moderate antibacterial activity. Hence the biosynthesized Be-AgNPs can be good source antioxidants, and anticancer agent's in future therapeutic applications.
\end{abstract}

Keywords: Green synthesis; Silver nanoparticles; Human teratocarcinoma cell lines; Antioxidant study; anti-tumorigenic activity; B.Erecta.

(c) 2020 by the authors. This article is an open-access article distributed under the terms and conditions of the Creative Commons Attribution (CC BY) license (https://creativecommons.org/licenses/by/4.0/).

\section{Introduction}

Over the past few decades' research on metal, nanoparticles gained much interest by research fraternity due to its featured size, penetration capacity as well as their physical, chemical and biological properties. Due to which it has been treated as an emerging platform 
in the field of biomedical research. The earlier studies reveal the negative impacts of chemical and physical methods for the synthesis of metal nanoparticles, which result in the production of non-eco-friendly byproducts. So there is an increasing demand for green nanotechnology for the development of environment-friendly silver nanoparticles (AgNPs) [1]. Many biological approaches for both extracellular and intracellular synthesis of silver nanoparticles have been reported todate using various parts of plant materials [2-13] and also microorganisms, including bacteria, fungi [14]. The selection of silver nanoparticle for biosynthesis is a great choice because Silver hasa wide range of properties including antimicrobial property [15-18] silver nanoparticles cause DNA damage and finally cell death [19] and also shows adverse effects on cell wall formation, ATP production, cell respiration as well as genotoxicity. Silver nanoparticle biosynthesis simple, low cost and have several rapid strategies for production at large scale, which have proven to be great therapeutic agents in cancer treatment [20-21]. Since ancient times, it is well known that a wide range of plants exhibits abundance medicinal properties, namely antimicrobial, anti-defense, antioxidant, Anti-tumorogenic as well as in treating many gastrointestinal disorders. Boerhavia Erecta is an extraordinary plant species thatis useful and unique through its physical characteristics and genetic composition [22]. It belongs to the native of the United States, Mexico, Central America, and Western South America. Now it is present all over tropical and sub-tropical regions of the world.

Boerhavia Erecta, commonly known as Erect spiderling and is also called by Erect Boerhavia, Shweta (in Hindi) Pandari Punarnava (in Marathi) and adavi maamena, ataka maamidi, punarnava, thella attikimaamidi (in Telugu). It is a herbaceous member of family Nyctaginaceae and mainly used as a traditional medicinal plant in Africa [23]. The roots of Boerhavia Erecta are used as a diuretic, especially in India, in cases of Jaundice, enlarged spleen, gonorrhea and other internal inflammations as well as a stomachic, cardiotonic, hepatoprotective, laxative, anti-helminthic and also as a febri-fugic agent. At moderate levels, it was also used to treat Asthma[24]. In West and East Africa, the leaves are eaten as a vegetable and also used in the preparation of Sauces [23].

Ovarian cancer is one of the five causes of cancer-related deaths in women and comprises a histological and genetic broad range of tumors [25]. Ovarian cancer is the most gynecological malignancy and is often fatal, primarily due to the late detection in most of the patients because the symptoms are asymptomatic. Hence the treatment methods during the early stages are highly critical. According to the global estimates, 225,000 new cases are detected each year, and 140,000 people die annually of this disease[26 ].

In the present study, silver nanoparticles were synthesized using the leaf extracts of Boerhavia Erecta and characterized by various spectral methods like UV-visible spectroscopy, Particle size by DLS method, Zeta potential analysis, and FTIR analysis. The biomedical applications like antibacterial activity were also studied against four bacterial species using the disc diffusion methods, Antioxidant activity evaluation was performed by DPPH free radical scavenging Assay, and finally, cytotoxic screening activity of green synthesized silver nanoparticles (Be-AgNPs) was also performed by using Human Ovarian teratocarcinoma cell line (PA-1) by (3-(4,5-dimethyl thiazol-2-yl-25 diphenyl) tetrazolium bromide (MTT) Assay. 


\section{Materials and Methods}

\subsection{Collection of plant material.}

The leaves of Boerhavia Erecta were collected from the trees growing in and around Seshachalam Hills at Tirupati and Tirumala during November 2016. The collected leaves were then washed with tap water, followed by distilled water to remove the dust particles on the surface. Leaves were then shade dried and made into a fine powder using a blender mixer and stored in a dry container to carry out further experiments.

\subsection{Preparation of plant extract.}

Boerhavia Erecta leaf extract was prepared by weighing $1 \mathrm{gm}$ of dried leaf powder into a $250 \mathrm{ml}$ of Erlenmeyer flask, and $50 \mathrm{ml}$ of distilled water was added. The leaf solution was kept in a water bath at $70^{\circ} \mathrm{C}$ for 1 hour. After one hour, the sample was filtered through muslin cloth followed by using Whatman No.1 filter paper. The filtrate was then transferred into a sterile container, and from that filtrate $10 \mathrm{ml}$ solution was diluted to $50 \mathrm{ml}$ with sterile distilled water, and this diluted extract solution was used to the biosynthesis of silver nanoparticles (AgNPs) by the reduction of $0.01 \mathrm{mM}$ silver nitrate solution. The remaining filtrate stock solution was stored in the refrigerator until further use.

\subsection{Biosynthesis of eco-friendly silver Nanoparticles.}

$1 \mathrm{ml}$ of leaf extract was taken into the sterile boiling test tube, and $4 \mathrm{ml}$ of sterile distilled water followed by $10 \mathrm{ml}$ of an aqueous solution of $0.01 \mathrm{mM}$ Silver nitrate were added. Further, the sample is kept in a boiling water bath at $60^{\circ} \mathrm{C}$ for 5 minutes to 15 minutes. The sample was observed every 5 minutes in order to determine the color development.

\subsection{Spectral Characterization of biosynthesized Be-AgNPs.}

The biosynthesized silver nanoparticles from the Boerhavia Erecta leaf extracts were analyzedusing UV-Vis spectroscopy (NanoDrop 8000 Spectrophotometer, DST PURSE center, S.V. University, Tirupati) to detect the Surface Plasmon Resonance (SPR) with respect to the biosynthesized silver nanoparticles. The spectra were obtained in the range of 220750nm using distilled water as a blank. The Fourier transform-infrared spectrum (FT-IR) analysis was carried out to find out functional groups of secondary metabolites of leaf extract, which are responsible for the reduction and stabilization of AgNPs by using an FT-IR spectrometer ( Shimadzu IR instrument, SPMVV Mahila University, Tirupati). The purified AgNPs were mixed with $\mathrm{KBr}$ powder and pulverization to obtain the pellet. FTIR spectra were recorded in the frequency range of $400-4000 \mathrm{~cm}^{-1}$ in transmittance mode. The Particle size and Zeta potential analysis wereperformed by (Horiba Nanopartica SZ-100 Nanoparticle analyzer, DST PURSE center, S.V. University, Tirupati). The particle size was determined based on the Brownian motion relating to the size of the nanoparticles suspended in a liquid. The average hydrodynamic size ( $\mathrm{Z}$ average), size distribution (\% number distribution) of silver nanoparticles as a colloidal suspension were measured using dynamic light scattering (DLS), the surface charge of the silver nanoparticle was also determined. 


\subsection{Antibacterial activity of Be-AgNPs.}

The antibacterial activity of silver nanoparticles was evaluated against gram-positive Staphylococcus aureus and Bacillus subtilis as well as gram-negative Escherichia coli and Klebsiella pneumonia by disc diffusion method. The bacterial strains were maintained by DST PURSE Centre, S.V.University, Tirupati. Andhra Pradesh. India. Nutrient Agar (Himedia) was prepared for bacterial culture, according to the manufacturer's instructions. Immediately after autoclaving, the media was allowed to cool up to $40^{\circ} \mathrm{C}$ and the media was poured into the flat bottom glass Petri dishes placed on a level horizontal surface to obtain uniformity. Overnight bacterial cultures of both gram-positive and gram-negative inoculums were evenly spread on the surface of the solidified agar media in Petri dishes by using an L-shaped glass rod. $5 \mathrm{~mm}$ in diameter discs were prepared using sterile Whatman filter No.1 paper, and with the help of sterile forceps, discs were placed equidistantly on to each of the inoculated Petri plates, respectively. The biosynthesized silver nanoparticles at different concentrations $(20 \mu 1$ (20 $\mathrm{mcg}), 30 \mu \mathrm{l}(30 \mathrm{mcg}), 40 \mu \mathrm{l}(40 \mathrm{mcg})$ and $50 \mu \mathrm{l}(50 \mathrm{mcg})$ respectively were added on the discs with the help of micropipette using sterile micropipette tips. Antibiotic Levofloxacin disc (15 mcg, Himedia) was placed in the middle of the plate as a reference drug. The inoculated plates were incubated overnight at $37^{\circ} \mathrm{C}$ in an incubator. Microbial growth inhibition was determined by measuring the diameter of Zone of Inhibition (ZIO in $\mathrm{mm}$ ).

\subsection{Evaluation of Antioxidant activity of Be-AgNPs by DPPH Assay.}

The free radical scavenging activity was determined using 1,1-Diphenyl-2-picrylhydrazyl radical (DPPH) [27]. This method is based on the reduction of alcoholic DPPH solution in the presence of hydrogen donating antioxidant due to the formation of non-radical form DPPH-H by the reaction. By taking ascorbic acid as the standard and DPPH as a control, antiradical power was measured at an absorbance of $517 \mathrm{~nm}$ in UV-Vis spectrophotometer.

\subsection{Anticancer activity of Be-AgNPs.}

\subsubsection{Cell culture.}

Human ovarian teratocarcinoma cell line (PA-1) was obtained from NCCS, Pune, and maintained at an atmosphere containing $5 \% \mathrm{CO}_{2}$ at $37^{\circ} \mathrm{C}$ in DMEM media ( Sigma-Aldrich) with $10 \%$ FBS. After it attains 80-90\%confluence, the cells were used for in-vitro experiments. Cytotoxicity of Be-AgNPs onPA-1 cells was determined by seeded cells at a concentration of $5 \times 10^{3}$ cells/well in 96 -well plates and incubated at $37^{\circ} \mathrm{C}$ overnight. The cells were then treated with varying concentrations of Be-AgNPs $5 \mu \mathrm{g} / \mu \mathrm{l}, 25 \mu \mathrm{g} / \mu \mathrm{l}$ and $35 \mu \mathrm{g} / \mu \mathrm{l}$ in a fresh medium and incubated for specific time periods ( 24 and $48 \mathrm{~h}$ ). At the end of the incubation, $10 \mu \mathrm{l}$ of MTT [3-(4,5-dimethylthiazol-2-yl)-2,5-diphenyltetrazolium bromide;5mg/ml] was added to the cells with fresh medium $(100 \mu \mathrm{l})$ and incubated at $37^{\circ} \mathrm{C}$ until formazan crystals were formed. The formazan crystals were dissolved in $100 \mu 1$ of DMSO, and the reading was taken at $570 \mathrm{~nm}$.

Cell viability was calculated by taking: Test OD/Control OD x 100.

\section{Results and Discussion}

The synthesis of silver nanoparticles was carried out according to the method described earlier [6]. The synthesis of AgNPs by leaf extract of Boerhavia Erecta was investigated. After 
5 to 10 minutes of incubation, the light colorless reaction mixture turned to dark brown color (Fig. 1). The color change indicated the reduction of silver ions $\left(\mathrm{Ag}^{+}\right)$into $\operatorname{AgNPs}\left(\mathrm{Ag}^{0}\right)$. It is well known that Be-AgNPs exhibit a dark brown color in aqueous solution due to Surface plasmon resonance (SPR).

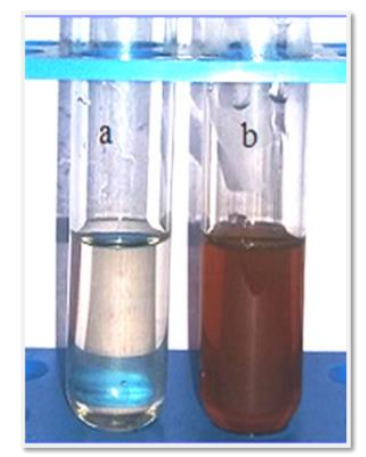

Figure 1. a. Leaf extract of Boerhavia Erecta and Silver nitrate before reduction. b.Be-AgNPs of leaf extract of Boerhavia Erecta after bioreduction.

\subsection{Ultraviolet-visible spectroscopy of Be-AgNPs.}

The bio-reduction of $\mathrm{Ag}+$ ions into $\mathrm{AgNPs}\left(\mathrm{Ag}^{0}\right)$ by using the leaf extract of Boerhavia Erecta was carried out from time to time by the sampling of the $1 \mu 1$ to $3 \mu l$ aliquots, and the optical absorbance was recorded on the Nanodrop $8000 \mathrm{UV}$-vis spectrophotometer in the wavelength range of $220 \mathrm{~nm}-750 \mathrm{~nm}$. The UV-visible spectra (Fig.2) of the bioreduced BeAgNPs solution showed an absorbance peak at $446 \mathrm{~nm}$, which is a characteristic Surface plasmon resonance (SPR) peak of silver nanoparticles. The size and shape of the Be-AgNPs depend on the absorbance peak. [28] The earlier studies on AgNPs reveals that if the SPR range of AgNPs is between 390nm to 470nm and in-between 400nm to $450 \mathrm{~nm}$ range, the AgNPs are found to be small and spherical in shape and the size of the AgNPs ranges of 20nm to $100 \mathrm{~nm}$ [29]. The SPR of Be-AgNPs is $446 \mathrm{~nm}$ indicating that the biosynthesised Be-AgNPs are small in size, and this further confirmed by Particle size analysis.

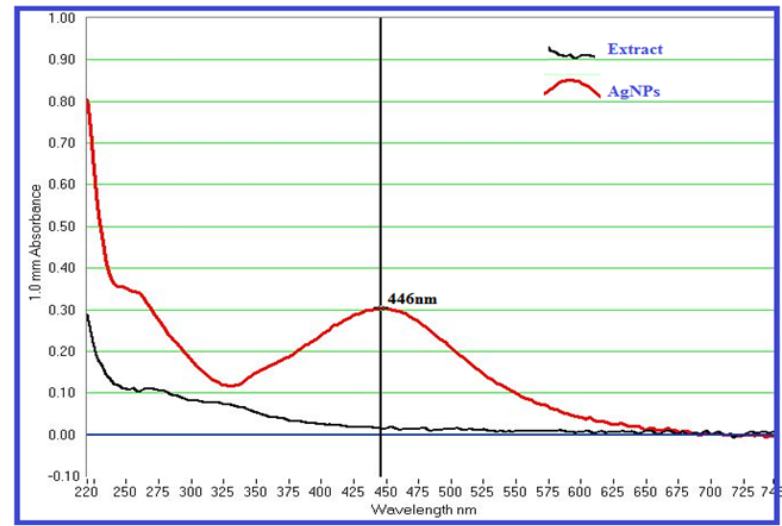

Figure 2(i). UV-VIS absorption spectra of leaf extract of Boerhavia Erecta

(ii). UV-VIS absorption spectra of Be- AgNPs synthesized from leaf extract of Boerhavia Erecta with $0.002 \mathrm{mM}$ silver nitrate.

\subsection{Fourier transform infrared (FTIR) spectra analysis of Be-AgNPs.}

The FTIR measurements were carried out to identify the biomolecules that are involved in capping and efficient stabilization of the biosynthesized silver metal nanoparticles. The FTIR spectral analysis of leaf extract of Boerhavia Erecta [Fig.3a.] showed intensive peaks at 3425, 
2924, 2855, 2310,1609, 1376, 1025, 891, 781 and $660 \mathrm{~cm}^{-1}$ and Bs-AgNPs [Fig.3b] showed peaks at 3355, 2922, 1638, 1410, 1242, 1057, 524476 and $449 \mathrm{~cm}^{-1}$ respectively [Table 1]. The FTIR spectrum of Be-AgNPs showed the band between 3355-3000 cm-1 corresponds to O-H stretching H-bonded alcohols and phenols. The peak found around 1500-1550 cm-1 showed a stretch for C-H bond. Peak around 1450-1500 cm-1 showed the bond stretch for N-H. The synthesized Be-AgNPs were surrounded by proteins and metabolites such as terpenoids having functional groups, confirmed that the carbonyl groups from the amino acid residues and proteins have the stronger ability to bind metal indicating that the proteins could form the metal nanoparticles to prevent agglomeration and thereby stabilize the medium. This suggests that the biological molecules could perform dual functions of the formation and stabilization of silver nanoparticles in the aqueous medium [30-32].

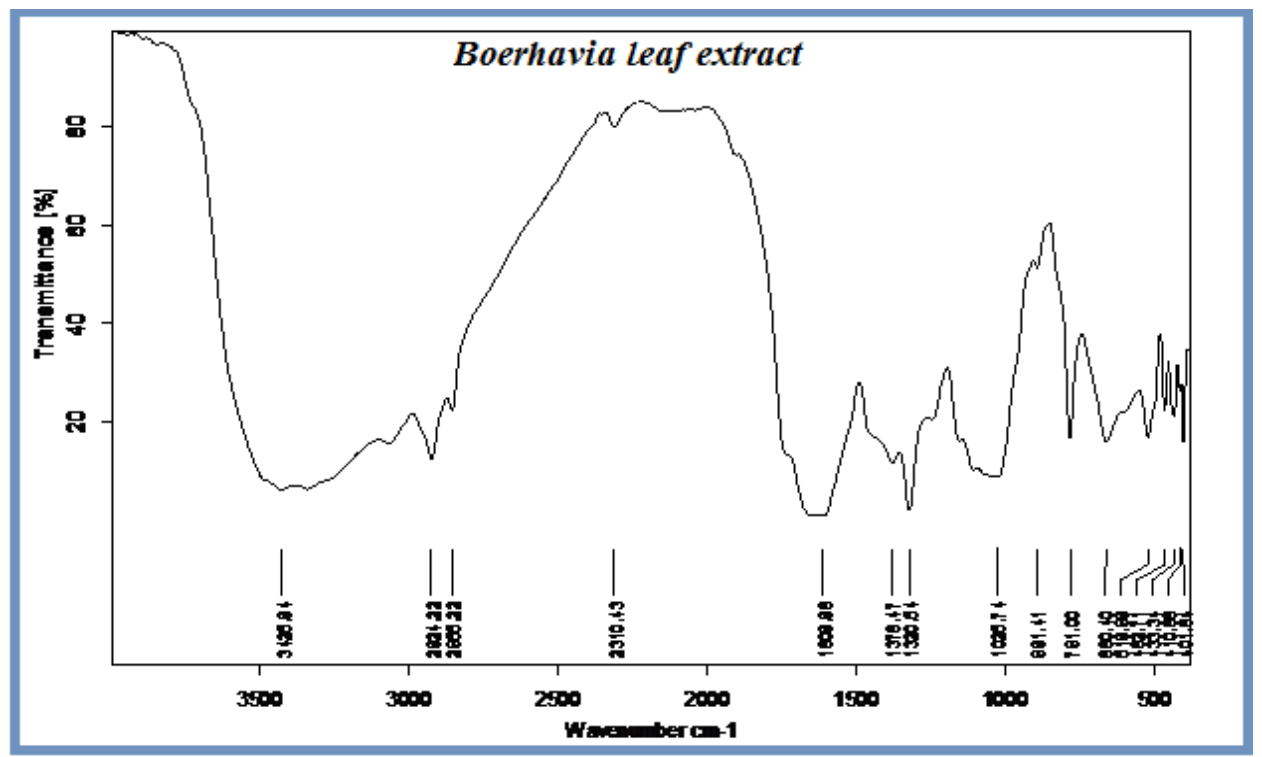

Figure 3.a. FTIR spectra of extract leaf extract of Boerhavia Erecta.

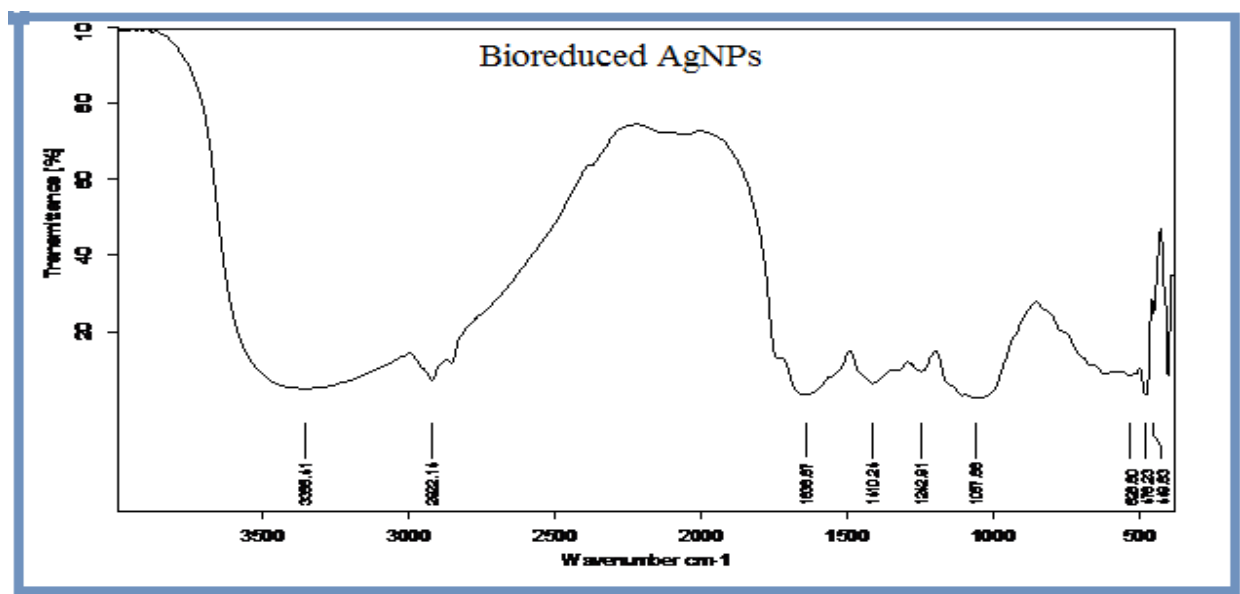

Figure 3.b. FTIR spectra of Be-AgNPs leaf extract of Boerhavia Erecta.

\subsection{Particle size and Zeta potential analysis of Be-AgNPs.}

The size of the biosynthesized Be-AgNPs was detected by the dynamic light scattering (DLS) method using the biosynthesized colloidal solution in which the Bs-AgNPs are polydispersed in nature. The distribution of Be-AgNPs isin the range of $8 \mathrm{~nm}$ to $32 \mathrm{~nm}$ in size, and the average size of biosynthesized Be-AgNPs was found to be $15.9 \mathrm{~nm}$ [Fig.4]. The zeta potential of Be-AgNPs was detected to be $-36.9 \mathrm{mV}$ [Fig.5], due to its high negative zeta 
potential, the Be-AgNPs lead to long term stability due to electrostatic repulsive force between the Be-AgNPs in the solution, and the results are similar to earlier reports [33-34].

Table 1. Functional groups in FTIR spectra analysis.

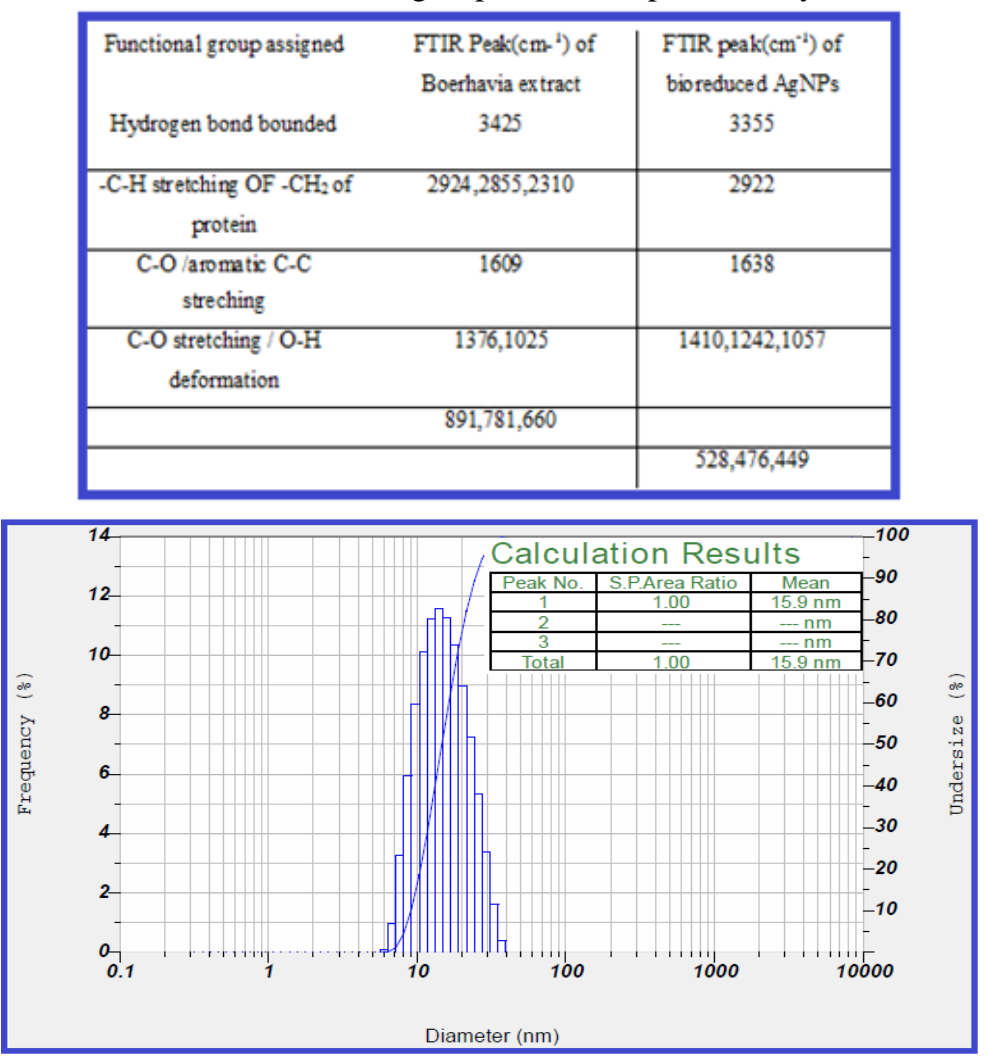

Figure 4. Particle size or DLS of Be- AgNPs biosynthesized using leaf extract of Boerhavia Erecta.

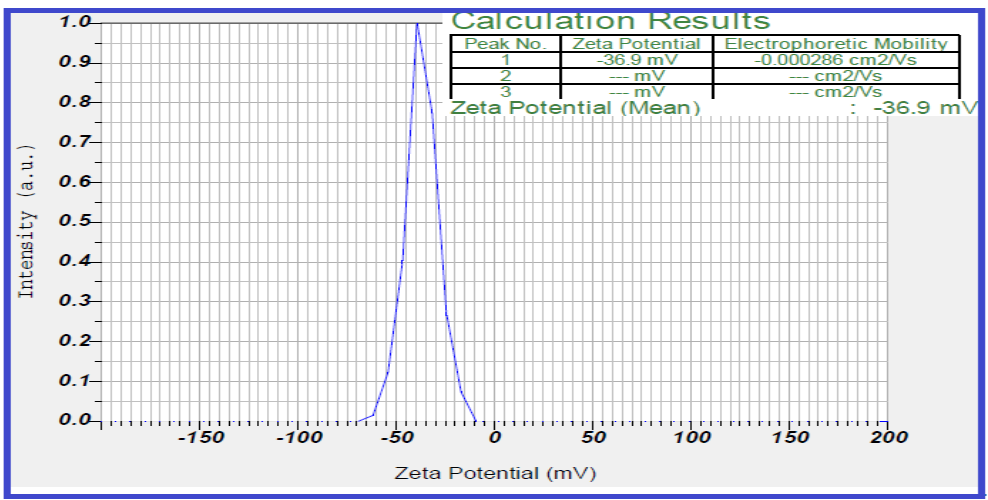

Figure 5. Zeta potential of AgNPs biosynthesized using leaf extract of Boerhavia Erecta.

\subsection{Antimicrobial studies of Be-AgNPs.}

The synthesized Be-AgNPs exhibited moderate or very less antibacterial activity against different pathogenic bacteria, and the zone of inhibition (ZOI) at different concentrations was reported [Fig.6] and in Table 2. Though earlier reports showed that AgNPs showed excellent antibacterial activity against different bacterial species, but in the present study they showed very less antibacterial activity and the highest ZOI was for E.coli, followed by S.aureus, B.subtilis, and K.pneumoniae, so we concluded that the Be-AgNPs exhibited almost less antibacterial activity than the antibiotic Levofloxacin. From the results of antimicrobial activity of Be-AgNPs we can further enhance the activity by increasing their concentrations as these are nontoxic and biocompatible [35-37]. 


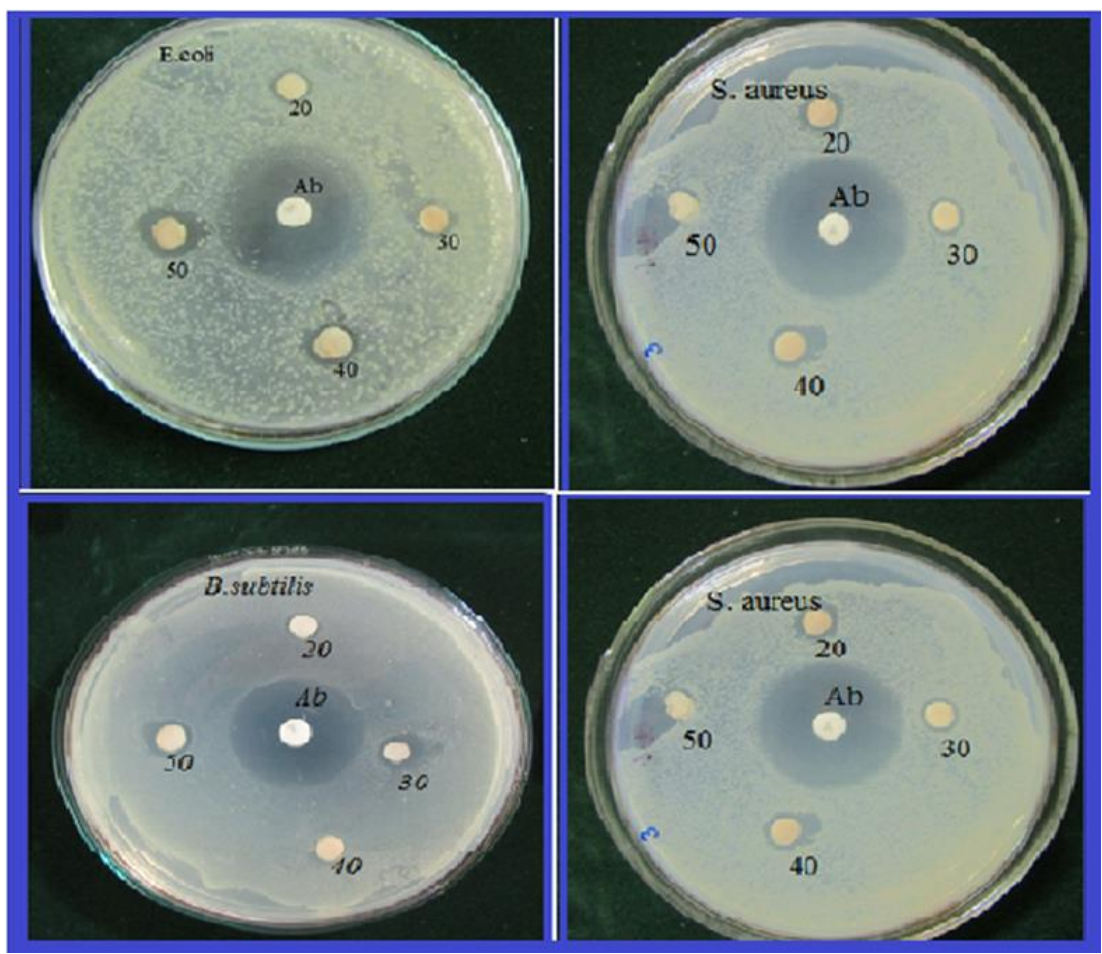

Figure 6. Antimicrobial activity of Be- AgNPs againstS. aureus, Bacillus cerus, and E.Coli and K. pneumoniae at different concentrations compared with a standard antibiotic (Himedia-Levofloxicin).

Table 2. Anti bacterial activity of biogenic synthesized AgNPs compared with Levofloxacin.

\begin{tabular}{|c|cc|cc|}
\hline \multirow{2}{*}{} & \multicolumn{5}{|c|}{ Inhibition zone in mm } \\
\cline { 2 - 5 } Levoflaxin & E.coli & B.sobtilis & S.aureus & K.poumoniae \\
\hline 20 & 30 & 30 & 28 & 25 \\
\hline 30 & 12 & 10 & 11 & 8 \\
\hline 40 & 10 & - & 9 & - \\
\hline 50 & 9 & 9 & 10 & - \\
\hline
\end{tabular}

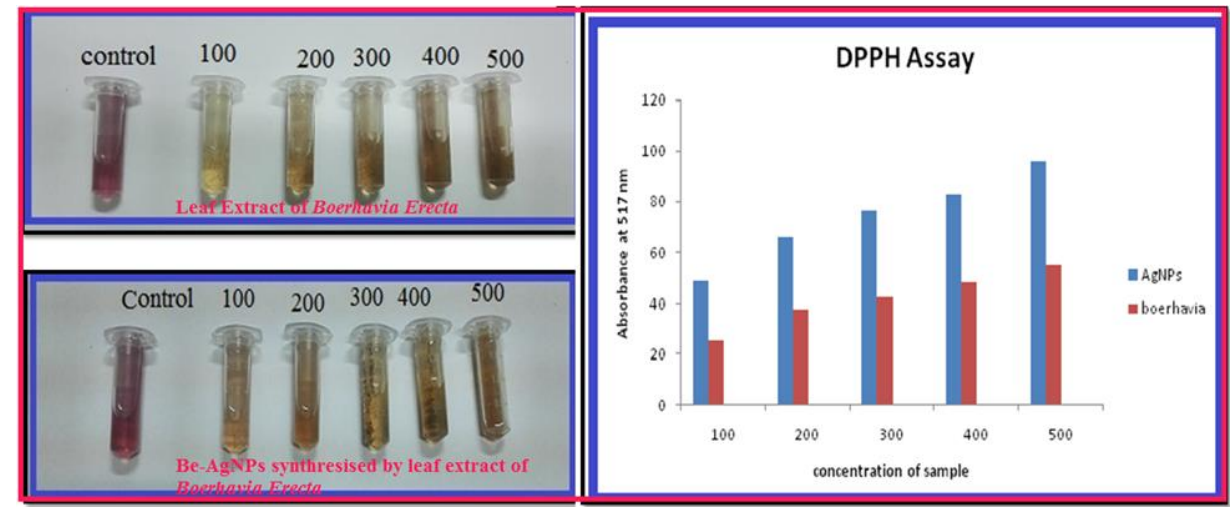

Figure 7. Antioxidant activity of using leaf extract of Boerhavia Erecta and the Be- AgNPs biosynthesized by leaf extract of Boerhavia Erecta.

\subsection{DPPH Assay of Be-AgNPs.}

The antioxidant activity of Boerhavia Erecta leaf extracts and biosynthesized BeAgNPs solution wasperformed by DPPH assay. The DPPH assay determined the ability of extracts and nanoparticles to scavenge the DPPH radical, from the results of UV-Vis 
spectroscopy absorbance values the free radical scavenging activity of the biosynthesized BeAgNPs was found to be greater than that of to plant leaf extract [Fig.7][Table 3]. In the presence of a hydrogen/electron donor, the absorption intensity is decreased, and the radical solution, the purple chromogen of DPPH radicals, is discolored to pale yellow hydrazine according to the number of electrons captured [38]. Our results indicate that the leaf extracts of B.erecta and Be-AgNPs can be used in functional foods as potential radical scavenging agents.

Table. 3. DPPH Assay.

\begin{tabular}{c|c|c} 
Concentration $(\mu \mathrm{l})$ & Bioreduced AgNPs & Plant extract \\
\hline 100 & 48.84 & 25.47 \\
\hline 200 & 65.94 & 37.86 \\
\hline 300 & 76.20 & 42.55 \\
\hline 400 & 83.17 & 48.34 \\
\hline 500 & 95.78 & 55.01
\end{tabular}

3.5.1. Cytotoxic activity of biosynthesized AgNPs against PA-1 cell lines.

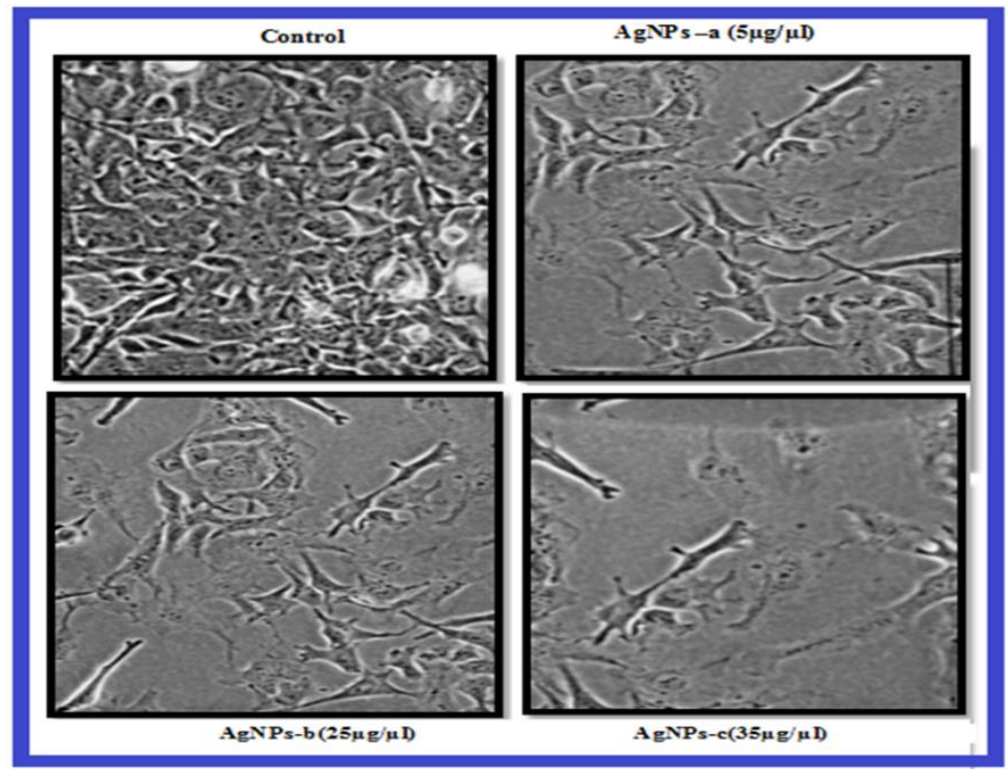

Figure 8. Anticancer activity of Be- AgNPs biosynthesized by leaf extract of Boerhavia Erecta in PA-1 Cell lines.

The Be-AgNPs synthesized by using the leaf extract of B.erecta had shown potent cytotoxic activity against the PA-1 cell lines, by verifying the proliferation percentage of PA1 cell lines at different concentrations of Be-AgNPs solution at different concentrations, we conclude that the effective cytotoxic activity was observed at $25 \mu \mathrm{l}(25 \mu \mathrm{g})$ concentration [Fig. 8] [Table 4].

Table. 4.Cytotoxic activities of biogenic AgNPs against PA-1 Cell lines.

\begin{tabular}{c|c|c|c|c} 
& $\begin{array}{c}\text { Amount } \\
\text { of plant sample }\end{array}$ & $\begin{array}{c}\text { Amount of } \\
\text { media added }\end{array}$ & OD value & Cell proliferation \% \\
\hline Control & $0 \mu \mathrm{l}$ & $200 \mu \mathrm{l}$ & 0.600 & 100 \\
\hline $\mathrm{AgNP} \mathrm{a}$ & $10 \mu \mathrm{l}$ & $190 \mu \mathrm{l}$ & 0.182 & 30.33 \\
\hline $\mathrm{AgNP} b$ & $25 \mu \mathrm{l}$ & $175 \mu \mathrm{l}$ & 0.068 & 11.33 \\
\hline $\mathrm{AgNP} \mathrm{c}$ & $35 \mu \mathrm{l}$ & $165 \mu \mathrm{l}$ & 0.058 & 9.66 \\
\hline DMSO & 0 & $200 \mu \mathrm{l}(\mathrm{DMSO})$ & 0.600 & 100
\end{tabular}

It was clearly observed that the percentage of cell viability decreases as the dosage of Be- AgNPs increases against cancer cells. An increase in the concentration of Be-AgNPs decreases the cell viability and increases the cytotoxicity against cancer cell lines. Be-AgNPs 
more than $87.3 \%$ inhibitions at the highest concentration of $25 \mu \mathrm{g} / \mathrm{mL}$ used in this study. Finally,we conclude that the Be-AgNPs have an excellent antitumorigenic property against Human teratocarcinoma cells (PA-1). The earlier reports also reveal similar types of results in various types of cancer [39-40].

\section{Conclusions}

Functionalized and eco-friendly nanoparticles are emerging in the field of cancer biology. The rapid biological synthesis of silver nanoparticles using Boerhavia erecta leaf extracts are in the estimated size range of $10-38 \mathrm{~nm}$ with an average size of $15.9 \mathrm{~nm}$. The BeAgNPs size was very small, which are surrounded by a thin layer of proteins and secondary metabolites which contain functional groups such as amines, alcohols, ketones, aldehydes, etc., which were confirmed from the characterization studies using UV-Vis spectrophotometer, FTIR, Particle size and Zeta potential Analyzer. Though the biosynthesized Be-AgNPs doesn't show good antibacterial activity, they have excellent antioxidant activity and anticancer activity. Therefore it is time for us to explore and identify our traditional therapeutic knowledge and plant sources and interpret it according to the recent advancements in fighting against oxidative stress in order to give it a deserving place. So in conclusion, we say that in a technological point of view, these obtained Be-AgNPs have potential applications in the biomedical field.

\section{Funding}

This research received no external funding.

\section{Acknowledgments}

The authors are grateful to DST PURSE center, Sri Venkateswara University, Tirupati, for providing facility to carryout apart of the research.

\section{Conflicts of Interest}

The authors declare no conflict of interest.

\section{References}

1. Singhal, G.; Bhavesh, R.; Kasariya, K.; Sharma, A.R.; Singh, R.P. Biosynthesis of silver nanoparticles using Ocimum sanctum (Tulsi) leaf extract and screening its antimicrobial activity. Journal of Nanoparticle Research 2011, 13, 2981-2988,https://doi.org/10.1007/s11051-010-0193-y.

2. Kotakadi, V.S.; Rao, Y.S.; Gaddam, S.A.; Prasad, T.N.; Reddy, A.V.; Gopal, D.V. Simple and rapid biosynthesis of stable silver nanoparticles using dried leaves of Catharanthus roseus. Linn. G. Donn and its anti microbial activity. Colloids Surf B Biointerfaces 2013, 105, 194-198, https://doi.org/10.1016/j.colsurfb.2013.01.003.

3. Gaddam, S.A.; Kotakadi, V.S.; Sai Gopal, D.V.R.; Subba Rao, Y.; Varada Reddy, A. Efficient and robust biofabrication of silver nanoparticles by cassia alata leaf extract and their antimicrobial activity. Journal of Nanostructure in Chemistry 2014, 4, https://doi.org/10.1007/s40097-014-0082-5.

4. Kotakadi, V.S.; Gaddam, S.A.; Subba Rao, Y.; Prasad, T.N.V.K.V.; Varada Reddy, A.; Sai Gopal, D.V.R. Biofabrication of silver nanoparticles using Andrographis paniculata. European Journal of Medicinal Chemistry 2014, 73, 135-140, https://doi.org/10.1016/j.ejmech.2013.12.004.

5. Venkata Subbaiah, K.; Susmila Aparna, G.; Sucharitha, K.V.; Prasad, T.N.V.K.V.; Gopal, D.V.R.S. Ficus Fruit-mediated Biosynthesis of Silver Nanoparticles and their Antibacterial Activity Against Antibiotic Resistant E. coli Strains. Current Nanoscience 2015, 11, 527-538, http://dx.doi.org/10.2174/1573413711666150126225951. 
6. Kotakadi, V.S.; Gaddam, S.A.; Venkata, S.K.; Sai Gopal, D.V.R. New generation of bactericidal silver nanoparticles against different antibiotic resistant Escherichia coli strains. Applied Nanoscience 2015, 5, 847-855, https://doi.org/10.1007/s13204-014-0381-7

7. Burdușel, A.-C.; Gherasim, O.; Grumezescu, A.M.; Mogoantă, L.; Ficai, A.; Andronescu, E. Biomedical Applications of Silver Nanoparticles: An Up-to-Date Overview. Nanomaterials 2018, 8, 681, https://doi.org/10.3390/nano8090681.

8. Palithya, S.; Kotakadi, V.S.; Pechalaneni, J.; Challagundla, V.N. Biofabrication of Silver nanoparticles by leaf extract of Andrographis serpyllifolia and their antimicrobial and antioxidant activity. International Journal of Nano Dimension 2018, 9, 398-407.

9. Nelaturi, P.; Sriramaia, N.; Nagaraj, S.; Kotakadi, V.S.; Veetil, A.; Kutty, V.; Pamidimukkala, K. An invitro Cytotoxic and Genotoxic Properties of Allmanda Cathartica L. Latex Green NPs on Human Peripheral Blood Mononuclear Cells. Nano Biomedicine and Engineering 2017, 2017, 314-323, https://doi.org/10.5101/nbe.v9i4.p314-323.

10. Sadeghi, B.; Jamali, M.; Kia, S.; Amininia, A.; Ghafari, S. Synthesis and characterization of silver nanoparticles for antibacterial activity. Int. J. Nano Dimens. 2010, 1, 119-124.

11. Sadeghi, B. Green synthesis of silver nanoparticles using seed aqueous extract of Olea europaea. International Journal of Nano Dimension 2014, 5, 575-581, https://doi.org/10.7508/ijnd.2014.06.010.

12. Habibi B., Hadilou H., Mollaei S., Yazdinezhad A.R.Green synthesis of Silver nanoparticles using the aqueous extract of Prangos ferulaceaeleaves.Int. J. Nano Dimens. 2017, 8, 132-141.

13. Kannan B, N.; Thoppil, J. Plant-mediated synthesis of Silver nanoparticles by two species of Cynanchum L. (Apocynaceae): A comparative approach on its physical characteristics. Int. J. Nano Dimens. 2018, 9, 104111.

14. Mukherjee, P.; Ahmad, A.; Mandal, D.; Senapati, S.; Sainkar, S.R.; Khan, M.I.; Parishcha, R.; Ajaykumar, P.V.; Alam, M.; Kumar, R.; Sastry, M. Fungus-Mediated Synthesis of Silver Nanoparticles and Their Immobilization in the Mycelial Matrix: A Novel Biological Approach to Nanoparticle Synthesis. Nano Letters 2001, 1, 515-519, https://doi.org/10.1021/n10155274.

15. Sondi, I.; Salopek-Sondi, B. Silver nanoparticles as antimicrobial agent: a case study on E. coli as a model for Gram-negative bacteria. Journal of Colloid and Interface Science 2004, 275, 177-182, https://doi.org/10.1016/j.jcis.2004.02.012.

16. Danilczuk, M.; Lund, A.; Sadlo, J.; Yamada, H.; Michalik, J. Conduction electron spin resonance of small silver particles. Spectrochimica Acta Part A: Molecular and Biomolecular Spectroscopy 2006, 63, 189-191, https://doi.org/10.1016/j.saa.2005.05.002.

17. Kim, J.S.; Kuk, E.; Yu, K.N.; Kim, J.-H.; Park, S.J.; Lee, H.J.; Kim, S.H.; Park, Y.K.; Park, Y.H.; Hwang, C.-Y.; Kim, Y.K.; Lee, Y.-S.; Jeong, D.H.; Cho, M.H. Antimicrobial effects of silver nanoparticles. Nanomedicine: Nanotechnology, Biology and Medicine 2007, 3, 95-101, https://doi.org/10.1016/j.nano.2006.12.001.

18. Feng, Q.L.; Wu, J.; Chen, G.Q.; Cui, F.Z.; Kim, T.N.; Kim, J.O. A mechanistic study of the antibacterial effect of silver ions on Escherichia coli and Staphylococcus aureus. J Biomed Mater Res 2000, 52, 662-668, https://doi.org/10.1002/1097-4636(20001215)52:4<662::aid-jbm10>3.0.co;2-3.

19. Morones-Ramirez, J.; Elechiguerra, J.; Camacho, A.; Holt, K.; Kouri, J.; Tapia, J.; Yacaman, M. The Bactericidal Effect of Silver Nanoparticles. Nanotechnology 2005, 16, 2346-2353.

20. Dipankar, C.; Murugan, S. The green synthesis, characterization and evaluation of the biological activities of silver nanoparticles synthesized from Iresine herbstii leaf aqueous extracts. Colloids Surf B Biointerfaces 2012, 98, 112-119, https://doi.org/10.1016/j.colsurfb.2012.04.006.

21. Jacob, S.J.; Finub, J.S.; Narayanan, A. Synthesis of silver nanoparticles using Piper longum leaf extracts and its cytotoxic activity against Hep-2 cell line. Colloids Surf B Biointerfaces 2012, 91, 212-214, https://doi.org/10.1016/j.colsurfb.2011.11.001.

22. Chen, S.H.; Wu, M.J. A Taxonomical Study of the Genus Boerhavia (Nyctaginaceae) in Taiwan. Taiwania 2007, 52, https://doi.org/10.6165/tai.2007.52(4).332.

23. Grubben, G.J.Plant Resources of Tropical Africa (PROTA). Volume 1. Prota, 2004.

24. Schmelzer, G.H.Boerhavia erecta L. PROTA (Plant Resources of Tropical Africa/Ressources végétales de l'Afrique tropicale). Wageningen, 2006.

25. Karnezis, A.N.; Cho, K.R.; Gilks, C.B.; Pearce, C.L.; Huntsman, D.G. The disparate origins of ovarian cancers: pathogenesis and prevention strategies. Nature Reviews Cancer 2017, 17, 65-74, https://doi.org/10.1038/nrc.2016.113.

26. WHO Malarvizhi, S.; Renuka, G. (Eds) Black's Medical-Surgical Nursing, First South Asia Edition, Chapter 40 Management of Women with Reproductive disorders page no. 936, eBook ISBN: 9788131254202, 2019.

27. Shareef, M.I.; Gopinath, S.M.; Gupta, A.; Gupta, S. Anti oxidant and anti cancer study of Boerhavia erecta. Int.J.Curr.Microbial .App.Sci.2017, 6, 879-895,https://doi.org/10.20546/ijcmas.2017.609.106.

28. Mock, J.J.; Barbic, M.; Smith, D.R.; Schultz, D.A.; Schultz, S.Shape effects in plasmon resonance of individual colloidal silver nanoparticles. The Journal of Chemical Physics 2002, 116,https://doi.org/10.1063/1.1462610. 
29. Venkata, S.; Gaddam, S.; Kotakadi, V.S.; Gopal, D.V.R.S. Multifunctional Silver Nanoparticles by Fruit Extract of Terminalia belarica and their Therapeutic Applications: A 3-in-1 System. Nano Biomedicine and Engineering 2018, 10, https://doi.org/10.5101/nbe.v10i3.p279-294.

30. Litvin, V.A.; Galagan, R.L.; Minaev, B.F. Kinetic and mechanism formation of silver nanoparticles coated by synthetic humic substances. Colloids and Surfaces A: Physicochemical and Engineering Aspects 2012, 414, 234-243, https://doi.org/10.1016/j.colsurfa.2012.08.036.

31. Litvin, V.A.; Minaev, B.F. Spectroscopy study of silver nanoparticles fabrication using synthetic humic substances and their antimicrobial activity. Spectrochimica Acta Part A: Molecular and Biomolecular Spectroscopy 2013, 108, 115-122, https://doi.org/10.1016/j.saa.2013.01.049.

32. Netala, V.R.; Bukke, S.; Domdi, L.; Soneya, S.; G. Reddy, S.; Bethu, M.S.; Kotakdi, V.S.; Saritha, K.V.; Tartte, V. Biogenesis of silver nanoparticles using leaf extract of Indigofera hirsuta L. and their potential biomedical applications (3-in-1 system). Artificial Cells, Nanomedicine, and Biotechnology 2018, 46, 11381148,https://doi.org/10.1080/21691401.2018.1446967.

33. Jadhav, K.; Deore, S.; Dhamecha, D.; H R, R.; Jagwani, S.; Jalalpure, S.; Bohara, R. Phytosynthesis of Silver Nanoparticles: Characterization, Biocompatibility Studies, and Anticancer Activity. ACS Biomaterials Science \& Engineering 2018, 4, 892-899, https://doi.org/10.1021/acsbiomaterials.7b00707.

34. El-Naggar, N.E.-A.; Hussein, M.H.; El-Sawah, A.A. Phycobiliprotein-mediated synthesis of biogenic silver nanoparticles, characterization, in vitro and in vivo assessment of anticancer activities. Scientific Reports 2018, 8, https://doi.org/10.1038/s41598-018-27276-6.

35. Fatema, S.; Shirsat, M.; Farooqui, M.; Pathan, M.A. Biosynthesis of Silver nanoparticle using aqueous extract of Saraca asoca leaves, its characterization and antimicrobial activity. Int. J. Nano Dimens. 2019, 10, 163-168.

36. Nahar, K.; Aziz, S.; Bashar, M.S.; Haque, M.D.A.; Al-Reza, S.M.D. Synthesis and characterization of Silver nanoparticles from Cinnamomum tamala leaf extract and its antibacterial potential. Int. J. Nano Dimens.2020, 11, 88-98.

37. Bangale, S., Ghotekar, S. Bio-fabrication of Silver nanoparticles using Rosa Chinensis L. extract for antibacterial activities. Int. J. Nano Dimens. 2019, 10, 217-224.

38. Locatelli, M.; Gindro, R.; Travaglia, F.; Coïsson, J.D.; Rinaldi, M.; Arlorio, M. Study of the DPPH scavenging activity: Development of a free software for the correct interpretation of data.Food Chemistry2009, 114,889-897.

39. Nakkala, J.R.; Mata, R.; Sadras, S.R. Green synthesized nano silver: Synthesis, physicochemical profiling, antibacterial, anticancer activities and biological in vivo toxicity. J Colloid Interface Sci 2017, 499, 33-45, https://doi.org/10.1016/j.jcis.2017.03.090.

40. Roshni, K.; Younis, M.; Ilakkiyapavai, D.; Basavaraju, P.; Puthamohan, V.M.Anticancer Activity of Biosynthesized Silver Nanoparticles using Murraya koenigii Leaf Extract against HT-29 Colon Cancer Cell Line. J Cancer Sci Ther2018, 10,https://doi.org/10.4172/1948-5956.1000521. 